\title{
JARDINAGEM DE GUERRILHA: INSTRUMENTALIZANDO O FORTALECIMENTO DA FUNÇÃO SOCIAL DA PROPRIEDADE
}

\section{Ana Carolina Amaral de Pontes* Daniel Gonçalves de Oliveira**}

\section{RESUMO}

Este artigo reflete sobre como estratégias de jardinagem de guerrilha podem instrumentalizar o fortalecimento da função social da propriedade. Tanto como forma de pressão sobre a qualidade dos espaços ofertados pelo poder público para convivência e coletividade, na qualidade e manutenção de praças e parques, como para fiscalização do estado de terrenos abandonados, subutilizados e que geram risco para a coletividade e a segurança pública. Essas estratégias também podem contribuir para fortalecer o conceito de uso digno e exploração ambientalmente correta, em um país onde quantidade considerável de pequenas e pequenos produtores não detêm propriedades, por situações de grilagem de terras e outras. Urge um Direito que, em visão decolonial, amplie o tratamento da função social da propriedade e da produção coletiva.

Palavras-chave: jardinagem de guerrilha; função social da propriedade; decolonialismo; produção coletiva; produção sustentável.

\section{GARDENING OF GUERRILLA: INSTRUMENTALIZING AND STRENGTHENING OF THE SOCIAL FUNCTION OF THE PROPERTY}

\begin{abstract}
This paper examines how guerrilla gardening strategies can strengthen the social function of property. Both as a means of pressure on the quality of spaces offered by the public administration, concerning maintenance of squares and parks, and on the supervision of vacant or underutilized lots, which generate risks for society and public safety. These strategies can also contribute to strengthen the concept of adequate and environmentally correct usage of land, in a country where a great amount of small producers do not hold property, because of fraudulent ownership ("grilagem") and other reasons. A new Law, with a decolonialized view, is urgent, so that it broadens legal treatment of the social function of property and of collective production.
\end{abstract}

Keywords: guerrilla gardening; social function of property; decolonialism. collective production; sustainable production.

\footnotetext{
* Professora Adjunta da UFRPE- UAG. Doutora em Educação pela Universidade Federal de Pernambuco. Mestre em Teoria Geral do Direito pela Universidade Federal de Pernambuco. Email: professoraanapontes@ gmail.com.

** Advogado e Professor universitário. Mestre em Direito Agrário pela Universidade Federal de Goiás. Especialista em Direito Civil e Processual Civil. Email: advgdanieloliveira@gmail.com.
} 


\section{NOTAS INTRODUTÓRIAS}

Nenhuma construção histórica é igual a outra. Diferenças de gênero, classe, raça e etnia, entre outras, fazem que as histórias sejam diversas, ainda que na mesma coletividade. Considerando que a narrativa oficial e constantemente repassada também costuma ser oficializada por um grupo dominante, hegemônico e colonialista, é preciso reconhecer uma necessidade emergente de mudança de paradigma tanto regional quanto internacional. Entre as mudanças mais significativas, a queda dos regimes ditatoriais dominantes (apesar dos atuais ensaios de retorno) e o reconhecimento de um Estado pluralista, multicultural, garantido, ainda que tenuamente, pelas constituições republicanas. O objetivo deste trabalho é identificar de que forma a luta pelo ideal da função social da propriedade pode contar com práticas sociais e instrumentos para fortalecer a ação coletiva; no caso, a jardinagem de guerrilha - em uma possibilidade hermenêutica que possibilite visão atenta às diferentes perspectivas de uma sociedade fundamentada na coletividade. Discutiremos inicialmente o conceito de função social da propriedade e de jardinagem de guerrilha como percepção do direito ao espaço público, tanto na visão do combate à terra improdutiva como na da transformação de posse em propriedade, como instrumento que denota o ânimo de utilização da terra. A intenção é procurar compreender de que forma a função social da propriedade pode ser fortalecida a partir de ações como as praticadas pela jardinagem de guerrilha, dentro do senso comunitário, do agir coletivo e da redução das desigualdades.

Neste artigo, são temas centrais a necessidade de reflexão sobre jardinagem de guerrilha como técnica e estratégia de ocupação individual e coletiva e as perspectivas de contribuição desta para compreensão de função social da propriedade que a fortaleça. Tal visão tem por objetivo trazer análise que contribua para ampliar as discussões sobre a prevenção de violações do direito ao espaço público, à habitação, à coletividade e à cidade. A temática mostra-se fortemente necessária, justificada tanto pelas recentes discussões e eventos envolvendo perda do espaço público pelas pessoas como vocação de congregação, lazer, união e diversão, quanto por motivos de segurança e pela perda de expressão das coletividades. O problema consiste em investigar a clareza entre a ausência de debate dos equipamentos públicos e do uso privado das 
propriedades para os desdobramentos possíveis de fortalecimento da compreensão generalizada da função social da propriedade.

\section{FUNÇÃO SOCIAL DA PROPRIEDADE NO ORDENAMENTO JURÍDICO BRASILEIRO}

O Brasil notabilizou-se pela exploração inicial de pau-brasil e, posteriormente, da canade-açúcar. Metais ainda não haviam sido descobertos, só se consolidando sua pesquisa e extração ao interiorizar-se a colonização.

A escravidão indígena durou cerca de cem anos, minada pelas revoltas indígenas (mais fortalecidas do que na escravidão negra, devido ao conhecimento geográfico) e por pressão jesuítica. Em 1549, a vinda de escravos e escravas de forma esporádica, como "parte da bagagem" de portugueses e portuguesas é reforçada por um decreto na regência de D. Catarina para que senhores de engenho importassem até 120 escravos por ano.

Quando o açúcar brasileiro toma a dianteira da produção mundial, a escravidão passa a ser largamente utilizada, dando ao país o feitio histórico conhecido. O período de fortalecimento açucareiro trouxe cerca de 500 mil pessoas escravizadas para o Brasil, o que se reforçou no período mineratório, com mais de um 1,7 milhão de pessoas. Apesar da suposta extinção do tráfico no Brasil, em 1831, ele perdura até 1850, estimando-se nesse período proibido a entrada de cerca de 500 mil pessoas em situação de escravizamento (PONTES, 2017).

Paralelamente, o Brasil adotava o sistema de capitanias hereditárias. Os chamados donatários deveriam povoar essas faixas de terra, explorá-las à sua expensa e governá-las, distribuindo sesmarias e com direito a escravizar indígenas, sempre em nome da Coroa Portuguesa. As sesmarias não poderiam ser conferidas aos chamados hereges, que incluiriam pessoas de origem árabe, judaica, indígena e negra. $\mathrm{O}$ instrumento previsto de retomada por improdutividade da terra foi claramente ignorado.

As raras retomadas no período colonial cuja documentação venceu o tempo apontavam evidências de disputas políticas que passam muito distante de razões produtivas, não muito diferentes das situações contemporâneas, infelizmente. 
No período de 1850 , com a chamada Lei de Terras, foi organizada uma estratégia de limitação de poder da população de pequenos posseiros e posseiras, pessoas libertadas recentemente da condição de escravas e imigrantes. Apesar da pressão para fim da escravidão, focou-se o contingente populacional de futuros consumidores e consumidoras, mas evitando que alterassem sua condição adquirindo terras legalmente. Observa José Murilo de Carvalho que a Lei de Terras constituiu o casamento do capital com a propriedade imobiliária (CARVALHO, 1980 , p. 78). Surgem, contudo, as chamadas "brechas camponesas", que constituíam uma economia alimentar paralela, complementar a monoculturas como a de açúcar no Nordeste, baseando-se na produção de alimentos em terras cedidas às margens das plantações de cana e abastecendo mercados locais além das próprias famílias, como explica CARDOSO (1987, p. 97 120). Com terras cedidas apenas provisoriamente, a tendência histórica na segunda metade do século XX foi a privação desse acesso limitado à terra, com expulsão das famílias camponesas.

É na lacuna de interação adequada entre o Direito, as normas e a historicidade que se traz esta reflexão: compreensão da função social da terra, desmerecida diante da configuração do direito de propriedade no Brasil, que sofre, mesmo nos dias atuais, as injunções dessas experiências coloniais.

Contemporaneamente, as disputas de ocupação de terra por comunidades menos favorecidas, não raro descendentes das mesmas populações vulneráveis historicamente sem acesso à terra (como quilombolas, ribeirinhos, indígenas e, sobretudo, campesinos), experimentam dificuldades profundas para configurar a boa fé da posse, para serem ouvidas e consideradas elegíveis para transmutação em propriedades pelo estado e mesmo para receber auxílio institucional destinado a fortalecer situações de usucapiões coletivas, por exemplo.

De outro lado, o movimento das guerrilhas verdes discute o espaço urbano e seu aproveitamento, equipamentos públicos e arborização. Pouca atenção se dá a um movimento constante em situações de ocupação, principalmente em zonas rurais ou semiurbanas: a arborização, ajardinamentos e pequenas hortas como ações de cuidado com a posse e enquadramento nos critérios jurídicos elegíveis para a usucapião social, que requer boa fé, tempo mínimo de cinco anos, máximo de 250 metros em área urbana ou 50 hectares em área rural e demonstração de moradia ou trabalho. Em consonância com as características da função social da propriedade (já que o aspirante a usucapião busca confirmar-se como proprietário ou 
proprietária), há necessidade de junção do respeito às regras do trabalho e aos aspectos ambientais.

É o agir no cuidado que deveria caracterizar a posse que se almeja transformada em propriedade. A jardinagem de guerrilha insere-se na discussão de forma provocativa como elemento enfatizador do desejo de permanência, frequentemente minado por ameaças de despejo.

A epistemologia decolonial encontra menos espaço no Direito do que merece. Ganha espaço na academia, mas, principalmente, em movimentos sociais independentes do estado, como coletivos e ONGs (GOHN, 2011). Isso é esperado, pois parte significativa dos sujeitos coletivos apontados (grupos de feministas, de indígenas, de feminismo negro e de movimentos periféricos) tradicionalmente encontra espaço para partilhar seus saberes no terceiro setor e, sobretudo, nos movimentos sociais.

Inicialmente, ela notabilizou-se por questionar a dependência dos países ditos em desenvolvimento perante a hegemonia dos países europeus, nas dimensões de saber, existir e poder. Esta nova forma de perceber o mundo e as relações de poder busca ações e maneiras de pensar que sejam inerentes às suas culturas e reagir diante de um ordenamento que, ao globalizarse, acaba por silenciar aqueles vistos como integrantes de saber e cultura econômica ou epistemologicamente considerada inferior.

O pensamento decolonial encontra registros em tempos recuados. Grupos étnicos diversos, em especial povos originários, reclamavam seu direito à alteridade e a permanecer em sua esfera cultural. Esse respeito não apenas lhes foi dificultado. Se de alguma maneira perduram seus saberes e visões, foi por enfrentamento e resistência (MIGNOLO, 2015; ESCOBAR, 2013).

O giro decolonial contou com contribuições do Grupo Modernidade/Colonialidade na América Latina (BALLESTRIN, 2013). Os principais conceitos trabalhados pela corrente compreendem as noções de colonialismo, modernidade, interculturalidade, colonialidade do poder, saber e ser. Aqui se perquire sua possibilidade na crítica às lacunas da hermenêutica tradicional, usando a teoria decolonial para uma hermenêutica comprometida com a inclusão.

Camila Klein de Oliveira (2016) descreve bem o percurso decolonial até as normas em países latinos: 
[...] Podemos encontrar o giro decolonial tanto na última Constituição da Bolívia quanto na do Equador. Para muitos críticos, esses países adotaram um marxismo indígena respaldando-se no conceito de emancipação da Escola de Frankfurt. Entretanto, Souza (2012) esclarece a diferença entre esse conceito e o de libertação utilizado pelos intelectuais da vertente em estudo. A emancipação de acordo com o referido autor e também para Dussel (2011), nasce, a priori, com o Iluminismo e serve como alicerce para a Revolução Americana e também para a Francesa em 1789; serve então para emancipar e dar a ascensão necessária para a burguesia. Posteriormente, na Revolução Proletária ocorrida na Rússia em 1917 é que a ideia de emancipação começa a ser utilizada pelos marxistas, tornando-se o alvo de Marcuse na primeira geração da Escola de Frankfurt.

Por conta disso, Dussel (2011) prefere utilizar para o contexto da América Latina o termo libertação, pois o objetivo é desamarrar-se dos domínios europeus, sejam vindos das ideologias esquerdistas ou de direita. Mignolo (2008) pondera que, assim como o termo decolonização, libertação também faz giro geopolítico do discurso, pois, ao utilizar o conceito de emancipação, cai-se nas teias da modernidade europeia. Mesmo os marxistas deixam como discussão periférica a conjuntura histórica dos grupos não europeus, das etnias não ocidentais, fazendo parte também do conjunto da colonialidade.

Esclarece que nas constituições se inseriu a chamada cidadania ampliada, pela qual se abordam as especificidades étnicas dos variados povos que constituem uma nação. A participação política tanto no Equador quanto na Bolívia dá-se de forma expansiva, e as leis são escritas de baixo para cima, de cujo processo a população participa ativamente, mediante referendos e movimentos sociais informais. Como pondera Oliveira, essa é uma das maneiras pelas quais se vê o pensamento decolonial saindo do campo teórico e adentrando o das ações (2016).

Outros autores e autoras reforçam que as novas constituições latino-americanas são resultado do novo constitucionalismo, que trouxe às nações latinas o desejo de olhar para suas próprias realidades. As novas cartas chamam atenção pela alta carga inovadora, que rompe padrões cristalizados nas normas constitucionais e assim compõem espaços para dialogar com grupos que tradicionalmente são secundarizados ou excluídos do debate público. Entre outras atualizações, fortalecem a versão da criação de um estado denominado de plurinacional (OLIVEIRA \& STRECK, 2012, p. 122).

Mesmo a busca do relato e das estratégias de sobrevivência no silenciamento das mulheres na história são ações decolonizantes. Reforçam-se as lutas de movimentos indígenas como povos originários, por exemplo, ao buscar recuperar e preservar seus saberes, inclusive 
jurídicos, que não são validados na concepção contemporânea por uma parcela acadêmica. Essa busca de preservação do "relato dos vencidos", individualmente, não permite refletir completamente sobre qual arcabouço teórico e histórico na trajetória brasileira vem sendo apoiada a narrativa predominante. $\mathrm{O}$ direito à propriedade é direito fundamental humano $\mathrm{e}$ ancorado nas normas constitucionais. $\mathrm{O}$ artigo $5^{-}$, caput, garante a propriedade como direito de todos, e seu inciso XXIII condiciona que a propriedade deverá atender sua função social.

O artigo 186 da Constituição de 1988 descreve os requisitos dessa função social, matéria também constante de normas infraconstitucionais. Encontrar-se tutelado no texto constitucional demonstra o aspecto público de que o direito à propriedade se reveste. Infelizmente, os muitos anos em que juristas limitaram o estudo e as regulamentações da propriedade à seara do direito privado, em especial do Direito Civil, contaminaram a visão dessa função até os dias atuais.

Recorda José Afonso da Silva (2010, p. 273-274):

a Constituição assegura o direito de propriedade, mas não só isso, pois [...] estabelece também seu regime fundamental, de tal sorte que o Direito Civil não disciplina a propriedade, mas tão-somente as relações civis a ela referentes [...] se pode falar em direito subjetivo provado (ou civil) do proprietário particular, como polo ativo de uma relação jurídica abstrata, em cujo polo passivo se acham todas as demais pessoas, a quem corre o dever de respeitar o exercício das três faculdades básicas: uso, gozo e disposição. Vale dizer, enfim, que as normas de Direito Privado sobre propriedade hão que ser compreendidas de conformidade com a disciplina que a Constituição lhe impõe.

Ainda que muitos e muitas imaginem ter sido superado o viés absoluto e exclusivista do direito de propriedade no Brasil, o fato é que ainda não está consolidada a visão do caráter público indispensável da função social da propriedade em nosso país.

Ao determinar que a propriedade deverá atender a função social, o/a legislador/a constituinte condicionou o exercício desse direito àquela destinação. $\mathrm{O}$ problema é que a flexibilidade de tal conceituação nas mudanças históricas acompanha as transformações das relações econômicas, de trabalho e culturais, nem sempre positivas, fortalecendo ou enfraquecendo a proteção de determinados institutos jurídicos.

No Brasil, a função social da propriedade foi positivada na Constituição de 1946 por meio da Emenda Constitucional 10, de 9 de novembro de 1964, mesmo ano de criação do 
Estatuto da Terra, que, no artigo $2^{\underline{o}}$, já condicionava a propriedade ao exercício de função social. $\mathrm{Na}$ Constituição vigente, o princípio encontra-se expresso no artigo 186:

Art. 186. A função social é cumprida quando a propriedade rural atende, simultaneamente, segundo critérios e graus de exigência estabelecidos em lei, aos seguintes requisitos:

I - aproveitamento racional e adequado;

II - utilização adequada dos recursos naturais disponíveis e preservação do meio ambiente;

III - observância das disposições que regulam as relações de trabalho;

IV - exploração que favoreça o bem-estar dos proprietários e dos trabalhadores.

A Lei 8.629, de 25 de fevereiro de 1993, que regulamenta os dispositivos constitucionais acerca da reforma agrária, no art. $9^{-}$, caput, prevê os requisitos aludidos no texto constitucional e, nos parágrafos, define como devem ser entendidos para haver cumprimento da função social da propriedade:

\footnotetext{
Art. $9^{\circ}[\ldots]$

$\S 1^{\circ}$ Considera-se racional e adequado o aproveitamento que atinja os graus de utilização da terra e de eficiência na exploração especificados nos $\S \S 1^{\underline{0}}$ a $7^{\underline{0}}$ do art. $6^{\circ}$ desta lei.

$\S 2^{\underline{0}}$ Considera-se adequada a utilização dos recursos naturais disponíveis quando a exploração se faz respeitando a vocação natural da terra, de modo a manter o potencial produtivo da propriedade.

$\S 3^{0}$ Considera-se preservação do meio ambiente a manutenção das características próprias do meio natural e da qualidade dos recursos ambientais, na medida adequada à manutenção do equilíbrio ecológico da propriedade e da saúde e qualidade de vida das comunidades vizinhas.

$\S 4^{\underline{0}}$ A observância das disposições que regulam as relações de trabalho implica tanto o respeito às leis trabalhistas e aos contratos coletivos de trabalho, como às disposições que disciplinam os contratos de arrendamento e parceria rurais. $\S 5^{\mathrm{o}} \mathrm{A}$ exploração que favorece o bem-estar dos proprietários e trabalhadores rurais é a que objetiva o atendimento das necessidades básicas dos que trabalham a terra, observa as normas de segurança do trabalho e não provoca conflitos e tensões sociais no imóvel.
}

A justiça social no campo está visceralmente ligada ao atendimento da função social da propriedade. A produtividade responde como aproveitamento eficiente da propriedade, tanto para desenvolvimento econômico do estado quanto para o de quem depende da terra para sustento. A justiça social deveria incluir o entendimento das justas relações de trabalho nas relações campesinas, que lamentavelmente sempre foram postergadas em direitos trabalhistas, retardando há décadas para proporcionar a trabalhadores e trabalhadoras do campo os mesmos direitos dos urbanos. Somam-se a necessidade de reduzir as disparidades e explorações nas relações 
contratuais e sociais relativas a propriedade rural e o respeito aos recursos naturais e ao meio ambiente, cada vez mais urgente.

Quando a lei condiciona o direito de propriedade (subjetivo) a utilização adequada dos recursos naturais e a preservação do ambiente, sinaliza que o titular da propriedade integra uma comunidade e deve utilizar a terra sem perder de alcance que sua ação não prejudique a coletividade. "Na doutrina jurídico-agrária, a função social da propriedade consiste na correta utilização econômica da terra e na sua justa distribuição, de modo a atender ao bem-estar da coletividade, mediante o aumento da produtividade e da promoção da justiça social" (ARAÚJO, apud LARANJEIRA, 2000, p. 154).

A função social da propriedade dimensiona a importância e o caráter público da propriedade e das relações jurídicas que a envolvem. Seus efeitos no gozo e exercício desse direito e sua influência sobre quem é proprietária/o e sobre o próprio poder público, todavia, ainda são insignificantes. Mesmo que a Constituição Federal preveja essa função, raras vezes é considerada quando um conflito por terra envolvendo grande número de pessoas pobres é submetido a apreciação judicial. Conquanto o art. 5º , XXXIII, advirta que a propriedade atenderá a sua função social e o art. 170, III, determine que a ordem econômica será fundada na valorização do trabalho humano e na livre iniciativa, tendo por fim assegurar a todos existência digna, conforme os ditames da justiça social, não se vê aplicação frequente dessa argumentação. Os princípios impostos pelo art. 182 são cristalinos. Seu $\S 2^{-}$dispõe que a propriedade urbana cumpre função social quando atende às exigências fundamentais de ordenação da cidade expressas no plano diretor. $\mathrm{O}$ art. 186, no capítulo relativo à política agrícola, fundiária e de reforma agrária, enumera requisitos a serem obedecidos pela propriedade rural, visando a prevenir suas/seus donos sobre em que espaço, tempo e modo será considerada cumpridora da função social: aproveitamento racional e adequado; utilização adequada dos recursos naturais disponíveis e preservação do ambiente; observância das normas sobre relações de trabalho; exploração que favoreça bem-estar de proprietários e trabalhadores.

Muito antes da Constituição de 1988, lei do período militar como o Estatuto da Terra e mesmo o Estatuto da Cidade (Lei 10.527, de 10 de julho de 2001) reforçaram a função social da propriedade. O Estatuto da Terra (Lei 4.504/1964), no art. 12, determinou que "à propriedade privada da terra cabe intrinsecamente uma função social e seu uso é condicionado ao bem-estar 
coletivo previsto na Constituição Federal e caracterizado nesta Lei." O Estatuto da Cidade, no parágrafo único do art. $1^{\circ}$, regulou "o uso da propriedade urbana em prol do bem coletivo, da segurança e do bem estar dos cidadãos, bem como do equilíbrio ambiental". Na parte final do art. 39, depois de abordar a função social da propriedade urbana, afinada com o plano diretor da cidade, procurou assegurar "atendimento das necessidades dos cidadãos quanto à qualidade de vida, à justiça social e ao desenvolvimento das atividades econômicas, respeitadas as diretrizes previstas no art. $2^{-}$desta Lei."

Com tantas razões, por que não são utilizadas amplamente tais previsões legais em favor do princípio constitucional da função social da propriedade? Revelam-se as forças econômicas históricas no país, que há décadas concentram poder superior ao próprio estado brasileiro, quando não simplesmente mantêm com este relações condenáveis de promiscuidade entre público e privado. Não se ingressará aqui em outro aspecto digno de nota: as relações complexas do poder do estado. Elas permitem, por meio de representantes políticos oriundos dessas mesmas classes detentoras de poder, permanecer nos Poderes Executivo, Legislativo e Judiciário e manter um princípio legal que figure no ordenamento jurídico não para transferir poder a quem seja prejudicado por sua violação, mas para "legitimar" esse mesmo ordenamento, fazendo passar por lei o que é apenas conveniência pessoal ou de grupos hegemônicos. No Brasil, poder e terra por muitos anos foram e em certa medida ainda são sinônimos.

Um dos piores aspectos desses conflitos, além das vidas perdidas nos direitos de quem é vítima do descumprimento das obrigações nela implicadas, consiste em que os efeitos dessa ilegalidade são irreversíveis, como em situações de dano ambiental e às pessoas envolvidas, que podem redundar em doenças e mortes. Nas palavras de Alfonsin (2015) "se uma determinada função é gravada como social, e deixa de funcionar como tal, isso afeta toda a sociedade para quem a dita função existe e é legalmente válida. Ela não se esgota numa relação interindividual apenas. Levado a juízo, um conflito relacionado com qualquer disfunção, como ocorre frequentemente em questões de terra, muito raramente uma tal obviedade é ponderada."

Esse desvio prejudica grande parcela de pessoas indeterminadas, titulares de um interesse público que não logra, muitas vezes, ser sequer reconhecido pelo Judiciário. A gritante concentração de terras brasileira alimenta parte considerável desses conflitos. Enquanto não sofrer combate necessário para sua desnutrição, tende a manter-se e crescer. Ampliar 
oportunidades no campo é decisivo para redução da desigualdade social evidenciada por diversos institutos de pesquisa e apontada há décadas, de Josué de Castro a tantos outros pesquisadores e pesquisadoras para os quais o problema da fome não consiste na qualidade da produção, mas no acesso à terra e no processo de desigualdade que se arrasta no Brasil há mais tempo do que a coletividade possa suportar para ser digna.

\section{JARDINAGEM DE GUERRILHA COMO DIÁLOGO COM ESPAÇOS PÚBLICOS E PRIVADOS}

As chamadas plantações de guerrilha têm como principais alvos os terrenos baldios abandonados e vazios urbanos para se implantar em espaços e trechos de solo não aproveitados nas cidades e os transformar. Ruas, bordas de vias e buracos em espaços verdes, minijardins e canteiros caracterizam o movimento, que já foi definido como cultivo de terra de outrem sem autorização.

Historicamente, pode-se apontar uma forma anterior de autorização similar, nas chamadas sociedades Vacant Lot Cultivation ("cultivo de lotes vazios", em inglês), que, no final do século XIX, eram autorizadas nos EUA por municipalidades a cultivar alimentos em terras públicas. Em outro momento histórico, nos anos 1970, a atuação de estudantes em Nova York na criação das chamadas "bombas verdes" ou bombas de sementes marcou mais fortemente não apenas o agir político, mas certa forma de independência do cultivo, com certo grau de aleatoriedade. $\mathrm{O}$ propósito da germinação estava mais ligado à transmissão de mensagem política do que a utilização perene do espaço em si. As bombas de sementes eram atiradas em lotes de terra vagos no Lower East Side de Manhattan, e a ação acabou por convencer os poderes públicos a criar os primeiros jardins comunitários, que sobrevivem. Gustavo Nagib (2016) observa que nas cidades, sobretudo em grandes metrópoles, as pessoas nem sempre possuem jardins ou quintais. Traduzindo livremente Reynolds, ele observa:

Mas algumas pessoas têm uma definição diferente de jardinagem. Eu sou uma delas. Eu não espero por permissão para me tornar um hortelão, cavo onde quer que eu veja potencial hortícola. Eu não só cuido de jardins que existem, como os crio em espaços negligenciados. Eu, e milhares de pessoas como eu, saímos de casa para plantar em terras que não possuímos. Nós vemos oportunidades em 
todo nosso entorno. Lotes vagos florescem como oásis urbanos, beiras de estrada encantam com suas flores e safras são colhidas de terra considerada improdutiva. Em todas as suas formas, estes cultivos têm sido conhecidos como jardins de guerrilha. Os ataques estão ocorrendo por toda parte e em toda escala - de missões individuais clandestinas a espetaculares campanhas hortícolas por células organizadas e politicamente engajadas. Isto é guerrilla gardening ["horticultura de guerrilha"]: o cultivo ilícito na terra de outrem (REYNOLDS, 2009, p. 4-5, grifo do autor, tradução nossa).

A partir do final da década de 1960, a agricultura urbana ganha destaque por meio de ações ativistas, em especial nos EUA. A contracultura emergente naquele momento inclui o movimento das hortas comunitárias. Elas começaram a aflorar em espaços públicos ou privados desocupados e localizados em áreas adensadas de importantes centros urbanos, como alternativa ao modelo político-econômico em curso. Em 1969, alunos da Universidade da Califórnia em Berkeley deixariam sua marca no espaço urbano do outro lado do país, em uma área de mais de $12.000 \mathrm{~m}^{2}$ entre as ruas Dwight e Haste. O Parque do Povo (People's Park), como foi denominado, pode ser considerado como a primeira grande atuação ativista nos tempos atuais que se expressou por meio de agricultura urbana. Observa Nagib (2016) que o Parque do Povo nasceu em 20 de abril de 1969, quando um grupo autodenominado "Comissão Robin Hood” tomou posse de um terreno baldio que pertencia à Universidade da Califórnia e pôs-se a trabalhar, eliminando ervas daninhas, plantando árvores e, talvez de modo mais promissor, fazendo uma horta. Dizendo-se "reformadores agrários", os militantes anunciaram que desejavam estabelecer ali um modelo para uma nova sociedade cooperativa, construída de baixo para cima, e isso incluía o cultivo da sua própria comida "não contaminada".

Citando o historiador Warren J. Belasco, Nagib relata que os acontecimentos no Parque do Povo marcaram a guinada da contracultura rumo ao verde, ao ideal pastoral que conduziria ao movimento comunal no campo, às cooperativas de produção de alimentos. A horta orgânica no Parque do Povo, logo imitada em terrenos urbanos de outros pontos do país, era concebida como uma espécie de modelo em pequena escala de uma sociedade mais cooperativa. A história de consolidação do Parque do Povo configura-se entre uma das mais simbólicas lutas sociais de fins da década de 1960. Continua Nagib (2016):

O então governador da Califórnia, Ronald Reagan, que nos anos 1980 se tornaria presidente dos Estados Unidos pelo Partido Republicano, considerava os ativistas como simpatizantes do comunismo e depravados sexuais. No dia 15 de maio de 
1969, a polícia armada foi enviada para fechar o parque. Naquela manhã, o [jornal] San Francisco Chronicle citou Reagan: "Se tem que haver um banho de sangue, então vamos acabar logo com isso". A notícia atingiu o campus. Um aglomerado de três mil pessoas já estava reunido em Sproul Plaza [também denominada de Sproul Hall - um importante local de ativismo estudantil dentro da Universidade da Califórnia, em Berkeley] para um comício sobre o conflito árabe-israelense, mas seu protesto mudou de foco. [...] Um líder estudantil tomou o palanque e gritou: Nome completo: Ronald Wilson Reagan. "Vamos tomar o parque de volta". A polícia desligou o sistema de alto-falantes e os manifestantes se levantaram e marcharam pela Telegraph Avenue entoando: "Nós queremos o parque". O episódio se tornou o que hoje é conhecido como Quinta Sangrenta [Bloody Thursday]. A massa enfurecida voltou um hidrante contra a polícia e jogou garrafas e pedras. Gás lacrimogênio foi arremessado pelas autoridades e momentos depois um carro da polícia foi virado e pegou fogo. Tiros foram disparados e James Rector, um espectador de uma cobertura, foi morto; outro homem foi cegado e centenas ficaram feridas. Reagan declarou estado oficial de emergência e convocou a Guarda Nacional. Após o episódio violento, os ativistas mudaram de tática. No protesto seguinte, reuniram-se 30 mil pessoas e, quando a Guarda Nacional posicionou-se apontando armas e arremessou gás lacrimogêneo, os manifestantes responderam jogando maços de margaridas. Neste episódio, não foram registradas lesões.

Finalmente, após um período de conflitos e reivindicações, em setembro de 1972, a Prefeitura de Berkeley arrendou a área do Parque do Povo à universidade, incentivando os cidadãos a melhorar o local. A Universidade da Califórnia é dona do terreno e, atualmente, gerencia e mantém o Parque do Povo, onde acontecem muitos festivais e eventos da comunidade. O parque possui um vasto gramado multiuso, banheiros, área de recreação infantil e de piquenique, quadras de basquete e hortas comunitárias.

Reynolds lançou o livro On guerrilla gardening, o tema tornou-se mais popular, com ações ocorrendo nas ruas de cidades estadunidenses, britânicas, holandesas, suíças, italianas, mexicanas, japonesas e canadenses. Parte significativa dessas ações é noturna, por diversas razões, em especial a titularidade alheia das terras utilizadas. Fontes de água autônoma ou a cooperação da vizinhança para o débil jardim ou horta são desafios comuns. Há quem tente viver das hortas, em movimentos mais estruturados que unem jardinagem de guerrilha, alimentação saudável e outras formas de protesto. Existe quem queira instrumentalizar a jardinagem para chamar atenção para outra causa. Há discussão perene da falta de espaços públicos acolhedores nas cidades. E há visões do movimento apenas como proposta de que uma fração de terra abandonada pode se tornar um jardim urbano e coletivo. Todas elas trazem a mesma provocação: "de quem é a cidade em que vivemos?" 
No Brasil, o Código Civil de 2002 adota as cláusulas gerais, ao lado da técnica regulamentar, como resultado de um processo de socialização das relações patrimoniais. Codificou-se, assim, a função social do contrato e da propriedade privada. Em um contexto no qual a condição de posseiro/a constitui a maioria na manutenção de bens imóveis no Brasil, o processo de regularização de bens tem entre seus obstáculos a desinformação para legalização, a inacessibilidade para acesso aos serviços registrais (cartórios) e a falta de recursos para pagamento de tributos e emolumentos, que são elevados e injustificados. Adversamente, militam contra a organização de pequenos e pequenas proprietárias de terra velhos conhecidos, como grileiros e a ausência de políticas públicas sérias de financiamento e apoio estatal para regularização fundiária em massa.

Como discutir posse e propriedade, sobretudo em bairros periféricos, fortemente caracterizados por situações de posse precária e circundados por falta crônica de estrutura de praças, escolas, serviços de saúde e áreas de lazer e de incentivo ao viver coletivo? Na constante especulação imobiliária e nomadismo forçado de classes economicamente mais vulneráveis, qual o espaço de apropriação dos conceitos de direito a moradia e concepção de espaço saudável urbano? Tecendo provocações para fomentar as reflexões sobre o diálogo da jardinagem de guerrilha em contexto de moradias populares e ocupações, a própria noção de função social da propriedade é desconhecida para muitas pessoas.

\section{JARDINAGEM DE GUERRILHA E ESTRATÉGIA DECOLONIAL PARA FORTALECER A FUNÇÃO SOCIAL DA PROPRIEDADE}

Para Larenz (2009), as normas jurídicas estão conectadas em um sistema amplo, e a interpretação de norma jurídica singular deve levar em consideração o contexto em que se encontre. $\mathrm{O}$ ordenamento jurídico está subordinado a princípios gerais, que buscam unificar as valorações decisivas do Direito e reduzir contradições. A compreensão das conexões de sentido que as normas encontram entre si e com os princípios diretivos do ordenamento em uma visão de conjunto (na forma de sistema) é das tarefas mais importantes da ciência do Direito (LARENZ, 2009, p. 621). 
Em outra ponta, Alexy (2008) sugere procedimento que assegure racionalidade na aplicação do direito e constitua objeto de uma teoria da argumentação jurídica. Já Dworkin (2008) assevera ser importante considerar que o positivismo trilhou diferentes caminhos e interpretações e, adotado como doutrina hermenêutica, fundamentou outras correntes teóricas. A ideia central à qual se opunha era a de que o 'direito' é um conjunto fixo de padrões de algum tipo; não é apenas de regras que o direito se constitui, nem estas dispõem tudo aquilo que é direito. Pelo contrário, o direito para Dworkin (2008) é, sobretudo, integridade. Essa visão assinala que pelo Direito passam princípios, história e comunidade, fundamentalmente. Regras são funcionalmente importantes ou desimportantes, mas, como parte do mesmo sistema, não se pode dizer que uma regra seja mais importante do que outra. Os princípios teriam uma dimensão que as regras não possuem, a dimensão do peso ou importância. Quando há possibilidade de mais de um princípio ser aplicado a determinado caso, a decisão de qual poderá resolvê-lo deverá levar em conta a força relativa de cada um, na chamada ponderação de valores. Dworkin (2008) sustenta que o julgamento implica não apenas aplicação de justiça, mas que a decisão necessariamente pressupõe compreensão da integridade do direito, que está associada a virtudes, como justiça, equidade e devido processo.

O autor reconhece o Direito como prática social, desenvolvida e intimamente relacionada com a construção social e diversos fenômenos sociais. Mas é prática que se distingue das demais por ser argumentativa. Se “o direito é um conceito interpretativo" (DWORKIN, 2008, p. 109) e, a partir disso, o "direito de uma comunidade é o sistema de direitos e responsabilidades que respondem a esse complexo padrão: autorizam a coerção porque decorre de decisões anteriores do tipo adequado" (2008, p. 116), o que faz uma teoria política completa do direito tratar tanto de seus fundamentos quanto de sua força.

É urgente observar que houve uma série de construções sociais, históricas, teóricas, políticas, econômicas e culturais que levaram as populações que sofrem recortes desfavoráveis de classe, raça e gênero a uma dominação violenta e excludente. A própria política de terras de grande parte dos países da América Latina favoreceu esse quadro de opressão, prolongando uma concepção marginalizada de pessoas sem acesso a terra perante os estados de que fazem parte. É nesse sentido que se buscam práticas para questionar essa realidade. A estratégia de jardinagem de guerrilha, ao mesmo tempo que questiona a improdutividade de terras públicas e privadas, tem 
a vantagem de apontar a falta de espaços públicos coletivos para utilização de equipamentos públicos em favor da população.

A jardinagem de guerrilha e a ideia de hortas urbanas constituem estratégias importantes para fortalecer a função social da propriedade no Brasil. Primeiro, porque podem representar consolidação necessária de múltiplas situações de posse no país, em especial de pequenos e pequenas agricultores e agricultoras, rurais e urbanas. A demonstração de posse mansa e pacífica e de ocupação e trabalho, provando utilização justa e produtiva do local, deve militar a favor de quem ocupa, embora haja longo caminho a ser incorporado na doutrina e na jurisprudência do país. Não por outra razão aqui se defende urgência da visão decolonial, que, ao considerar os recortes de classe, raça, etnia e gênero, pode compreender as peculiaridades de um Direito que até então tem atuado como elemento segregador e não integrativo.

Em segundo lugar, como forma de pressionar o poder público para melhor utilização do patrimônio público e investimento nos espaços de convivência e coletividade. As estratégias de jardinagem de guerrilha e de hortas urbanas chamam atenção para os terrenos abandonados, subutilizados e que prejudicam a coletividade e a segurança pública. Pressionam o poder público tanto para a função fiscalizatória como para a ausência de políticas públicas de investimento em equipamentos públicos como praças, parques e outros.

O desafio vem sendo pavimentar um caminho de interpretação decolonial no Direito brasileiro, que contemple integralmente as nuanças da coletividade e não apenas priorize propriedade e individualidade. Os vários modelos de urbanismo, dos mais funcionais aos mais utópicos, influenciaram as formas urbanas estruturadas por diferentes espaços verdes e agrícolas, mas ainda são desconhecidos no Direito. As “áreas verdes urbanas” possuem significados incompreendidos e representações sociais de natureza muito diversa, sejam praças, parques, matas e bosques urbanos ou espaços cultivados, ainda compreendidas em uma visão tradicionalista e cristalizada como de gestão exclusiva do estado e longe de atender aos anseios e outras formas de vivência. As muitas formas de criação de espaços coletivos e equipamentos públicos como hortas coletivas, readequação de terrenos baldios, terras agrícolas e espaços públicos produtivos, entre outros, não recebem do Judiciário o tratamento avançado devido, coerente com as necessidades contemporâneas. 


\section{CONCLUSÃO}

O Estado Democrático de Direito exige nova postura de juízes e juízas que exerçam atividade puramente cognoscitiva e mecânica, autorizando nova técnica legislativa por meio de cláusulas gerais, que não prescrevem norma de conduta, mas definem parâmetros de interpretação. Torna-se mais acentuada a missão, para que demonstrem por que certas condutas alicerçaram a solução da causa. $\mathrm{O}$ direito de propriedade só é eticamente válido se cumprida sua função social, cristalizando o valor socioeconômico da moradia para o direito de propriedade urbana e de produção de alimentos, para o direito de propriedade rural. O Código Civil adotou, também no direito de propriedade, a concepção de abuso de direito, tornando defesos atos que não tragam ao proprietário comodidade ou utilidade e sejam animados por intenção de prejudicar outrem, consoante o $\S 2^{\underline{o}}$ do art. 1.228 .

Intrinsecamente vinculados, propriedade rural e meio ambiente devem caminhar juntos, para que aquela não deixe de cumprir seu papel econômico, mas este não seja devastado em nome do capital ilimitado. Aqueles que utilizam o meio ambiente não podem fazê-lo indiscriminadamente, tampouco ignorar que, para exercer seus direitos, devem cumprir deveres maiores. A responsabilidade ambiental denota a supremacia que um direito difuso ostenta frente a interesses particulares. A preservação ambiental mostra-se mais relevante do que meios irresponsáveis de exploração dos recursos naturais. Não mina o uso da terra, mas impõe responsabilidade àqueles que não a utilizem de forma consciente, inclusive para recuperar o bem lesado. Como prevenir a subutilização e o abandono de terras diante de tanta necessidade de alimentos? Torna-se urgente não apenas pensar a função social da propriedade no que tange à má utilização ambiental, mas sua ociosidade como prejuízo ambiental.

Função social da propriedade não tem o mesmo significado valorativo para todos os povos de nossa sociedade. Em uma perspectiva decolonial aprende-se que, para as comunidades tradicionais, terra também se pode afigurar como parte da identidade, em definição complementar à legislativa e de até cunho principiológico. Impõe-se repensar o valor de estratégias para utilização de espaços públicos e privados, seja de forma coletiva, seja individual. O Brasil, por sua tradição colonial, criou milhões de situações de posses irregulares, principalmente de pequenos e pequenas agricultores e agricultoras, rurais e urbanas. Legalizá-las depende de 
política pública séria que poderia ser provocada com estratégias organizadas de jardinagem e guerrilha e hortas urbanas, entre outras, valorizando utilização justa e produtiva do local em favor de quem o ocupe, combinado com visão mais ampla por parte do Poder Judiciário, que compreenda, em uma visão decolonial, recortes de classe, raça, etnia e gênero. Esses movimentos são fundamentais como forma de pressão sobre a qualidade dos espaços ofertados pelo poder público para convivência e coletividade. As estratégias de jardinagem de guerrilha e de hortas urbanas chamam atenção tanto da qualidade e manutenção de praças e parques como para fiscalização do estado dos terrenos abandonados, subutilizados e que geram risco para a coletividade e a segurança pública.

Sem dúvida, ainda é utópico. Muitas mudanças, em sua gestação, foram consideradas inviáveis, para então desenvolver-se, a despeito da descrença geral. Acreditar "em flores vencendo canhões" pode ser difícil, especialmento em um tempo em que crescem a intolerância, o elogio da ignorância e a predominância do $e u$ sobre o nós. Nessas circunstâncias, acreditar em flores que rebentem asfaltos ainda serve para crer no rompimento dos sistemas para que brote um Direito decolonial, justo, que contemple terra para todas e todos, com justiça e produção coletiva e farta de alimentos.

\section{REFERÊNCIAS}

ALEXY, Robert. Teoria dos direitos fundamentais. São Paulo: Malheiros, 2008a. El concepto y la validez del derecho. São Paulo: Malheiros, 2008b.

ALFONSIN, Jacques Távora. A legitimidade popular para cobrar função social à propriedade. 13 maio 2015. Disponível em <https://is.gd/oKOunB > ou $<$ http://www.mst.org.br/2015/05/13/a-legitimidade-popular-para-cobrar-funcao-social-apropriedade.html >; acesso em 14 abr. 2019.

BRASIL. Constituição da República Federativa do Brasil. 5 out. 1988. 
BRASIL. Lei 8.629, de 25 de fevereiro de 1993.

CAPPELLETTI, Mauro. Juízes legisladores? Porto Alegre: Sergio A. Fabris, 1999.

CARDOSO, Cyro Flamarion. Escravo ou camponês? O proto-campesinato negro nas Américas. São Paulo: Brasiliense, 1987.

CARVALHO, José Murilo. Teatro de sombras: a política imperial. Rio de Janeiro: IUPERJ, 1980.

COELHO, Fábio Ulhoa. Curso de Direito Civil. Contratos. 26. ed. São Paulo: Saraiva, 2010. v. 9.

DWORKIN, Ronald. O império do direito. São Paulo: Martins Fontes, 2008.

ENGISH, Karl. Introdução ao pensamento jurídico. 6. ed. Trad. J. Baptista Machado. Lisboa: Calouste Gulbenkian, 2015.

GOHN, Maria da Glória. Movimentos sociais na contemporaneidade. Revista brasileira de Educação. v. 16, n. 47, 2011, p. 333-61.

LARANJEIRA, Raymundo (coord.). Direito Agrário brasileiro. São Paulo: LTr, 2000.

LARENZ, Karl. Metodologia da Ciência do Direito. 3. ed. Tradução de José Lamego. Lisboa: Calouste Gulbenkian, 2009.

MIGNOLO, Walter. Desobediência epistêmica: a opção descolonial e o significado de identidade em política. Cadernos de Letras da UFF. Dossiê: literatura, língua e identidade, n. 34, 2008, p. 287-324.

- Pensamiento decolonial, desprendimiento y apertura. In.: MIGNOLO, Walter (org.). Habitar la frontera: sentir y pensar la descolonialidad. Barcelona: CIDOB, 2015. Disponível em: $\quad<$ https://is.gd/YmZpYX >

$<$ http://www.cidob.org/content/download/64794/1995059/version/1/file/219-

324\%20HABITAR\%20LA\%20FRONTERA\%203\%20(3G)8.pdf >. Acesso em: 11 jan. 2019.

NAGIB, Gustavo. Agricultura urbana como ativismo na cidade de São Paulo: o caso da Horta das Corujas. São Paulo: USP. 2016.

OLIVEIRA, Camila Klen de. Breve introdução ao giro decolonial: poder, saber e ser.

Disponível em <https://bit.ly/2Gjsh1b > ou

$<$ http://www.pensaracademico.facig.edu.br/index.php/semiariocientifico/article/viewFile/53/38

>; acesso em 11 jan. 2019.

Revista de Direito Agrário e Agroambiental | e-ISSN: 2526-0081 | Goiânia | v. 5 | n. 1 | p. 40 - 59 |

Jan/Jun. 2019. 
PONTES, Ana. Escravidão por dívidas e as raízes do trabalho escravo na esfera rural, uma análise à luz das lacunas de criticidade no Direito Agrário Brasileiro. Revista Brasileira de Direito Agrário. CONPEDI, 2016.

REYNOLDS, Richard. On guerrilla gardening: a handbook for gardening without boundaries. London: Bloomsbury, 2008.

STRECK, Lênio Luiz. Hermenêutica jurídica e(m) crise: uma exploração hermenêutica da construção do Direito. 11. ed., rev., atual. e ampl. Porto Alegre: Livraria do Advogado, 2014. 